\title{
De trabajadores inamovibles a trabajadores móviles. El caso de los contratistas de una región vitícola de Mendoza, Argentina (1995-2010)*
}

\author{
Lorena POBLETE \\ Instituto de Desarrollo Económico y Social (IDES CONICET) \\ IDAES-Universidad Nacional de San Martín \\ lorena.poblete@conicet.gov.ar
}

Recibido: 02-11-2010

Aceptado: 26-04-2011

\section{RESUMEN}

El estatuto de contratista fue el pilar del modelo de organización del trabajo que caracterizó las regiones vitivinícolas de Mendoza (Argentina) hasta principios de los años 90. La particularidad de este estatuto es que instituyó la casa/trabajo, en tanto que unidad indivisible, como eje de estructuración de las relaciones laborales y sociales. Sin embargo, a partir de los años 90, la recomposición de la vitivinicultura trajo aparejada una reestructuración de las relaciones laborales que llevaron a la ruptura de esa unidad. El objetivo de este artículo es analizar la manera en que se quiebra la unidad casa/trabajo, y las consecuencias de esta ruptura para los contratistas en términos de recomposición de las relaciones laborales y de reestructuración del espacio social.

Palabras clave: trabajadores rurales, flexibilidad laboral, precariedad laboral, vitivinicultura, Argentina.

\section{From inamovable workers to moveable workers. The case of contratistas in Mendoza's wine region, Argentina (1995-2010)}

\begin{abstract}
Contratista's status was the core of the labour organisation model witch characterizes wines lands in Mendoza (Argentina) until the '90. Contratista's status particularity was it institutionalises house/work, as an indivisible unit, and this unit structures labour and social relationships. Nevertheless, since the '90, wine industry modernisation implies the reorganisation of labour relationships and broke this unit. The goal of this article is to analyse the way that this unit was broked, and the consequences these agriculture workers in terms of reorganisation of labour relationships and restructuring of social space.
\end{abstract}

* Esta investigación fue desarrollada en el marco del programa "Naturalización y legitimación de las desigualdades sociales en la Argentina reciente" dirigido por el Dr. Alejandro Grimson, en el IDAES, Universidad Nacional de San Martín (UNSAM). 
Keywords: Agriculture workers, labour flexibility, precarious jobs, grape growing and wine production, Argentina

\section{REFERENCIA NORMALIZADA}

Poblete, L. (2011). De trabajadores inamovibles a trabajadores móviles. El caso de los contratistas de una región vitícola de Mendoza, Argentina (1995-2010), Cuadernos de Relaciones Laborales, Vol. 30, núm. 2, p. 519-539.

SUMARIO: Introducción. 1. La casa y el trabajo como una unidad indivisible.1.1. El estatuto de contratista. 1.2. Del estatuto al mundo del contratista. 2. La casa y el trabajo como unidades independientes. 2.1. El proceso de recomposición de la industria vitivinícola. 2.2. La reestructuración del mundo del trabajo en Barrancas. 2.2.1. La ruptura de la unidad casa/trabajo: la pérdida del contrato. 2.2.2. La recomposición de las relaciones laborales: la casa con o sin trabajo. 3. Conclusión. 4. Referencias bibliográficas.

\section{Introducción}

El estatuto de contratista jugó un rol central en el modelo de organización del trabajo que caracterizó a las zonas vitivinícolas de Mendoza hasta principios de los años 90. La particularidad de este estatuto es que sitúa al trabajador en una posición intermedia entre el obrero rural y el arrendatario. Una de sus características más relevantes es que da lugar a relaciones laborales muy extendidas en el tiempo porque, aún si establece un contrato anual, éste puede renovarse indefinidamente.

Este estatuto estipula además que el trabajador tiene derecho a una vivienda en la propiedad agrícola. La casa y el trabajo forman así una entidad indivisible a partir de la cual se estructuraron las relaciones laborales en las explotaciones vitícolas de Mendoza. La subordinación de la residencia al trabajo funcionó como un elemento clave de fidelización de la mano de obra. Esta forma de organización y regulación del trabajo, caracterizada por la permanencia espacial y temporal, fue funcional a un sistema de producción relativamente estable dada la participación del Estado en la regulación del mismo (Ospital, 2009).

Desde los años 90, se observa un importante proceso de transformación de la vitivinicultura mendocina que resulta de la introducción de capitales extranjeros que invierten en la modernización tecnológica de esta agroindustria con el objeto de comercializar vinos finos en el mercado internacional. La incorporación de nuevas tecnologías trae aparejada la reducción del número de trabajadores no calificados y un aumento de los cuadros técnicos. A estos cambios tecnológicos se suma la adopción de estrategias empresariales asociadas con lo que algunos autores han denominado el "nuevo espíritu del capitalismo" (Boltanski y Chiapello, 1999). Este nuevo espíritu se manifiesta claramente en la gestión de recursos humanos. Con el objeto de alcanzar una mayor rentabilidad a través de la reducción de los costos laborales y de disminuir las responsabilidades patronales, los nuevos inversores rompen la unidad casa/trabajo. Esta unidad, que daba una enorme estabilidad a los trabajadores, producía, al mismo tiempo, una gran dependencia de los mismos respecto del empleador.

En este artículo, nos proponemos analizar la manera en que se quiebra esta unidad, y las consecuencias de esta ruptura para los contratistas en términos de recom- 
posición de las relaciones laborales y de reestructuración del espacio social. Para ello, se tomará como caso de estudio la región de Barrancas, donde realizamos diferentes trabajos de campo a lo largo de quince años, durante las cosechas de 1995, 1997, 1999 y 2010. El interés de este caso tiene que ver con el lugar que ocupa Barrancas en la producción de vinos y con la manera generalizada en la que se impone en esta región el nuevo modelo agroindustrial.

La región de Barrancas está ubicada en Maipú, al Sur-Este de la capital de Mendoza. Maipú es uno de los departamentos pioneros en el cultivo de la vid. Las primeras plantaciones datan de 1873 . En relación a la superficie cultivada, Maipú ocupa el $5^{\text {to }}$ lugar ya que posee el $8,6 \%$ del total. En cuanto a la producción de uvas destinadas a la vinificación, Maipú está en el $4^{\text {to }}$ lugar con el 8,6\% del total. Sin embargo, en lo que se refiere a la producción de vinos, es el segundo productor de Mendoza concentrando el 14\% del total de hectolitros producidos (INV, 2008).

Barrancas vivió activamente el proceso de transformación de la agroindustria vitivinícola iniciado en los años 90 . Su superficie cultivada casi se triplicó durante esa década por la introducción del riego por goteo. Además, las mayores explotaciones de la zona representaron casos paradigmáticos de transferencia de empresas familiares a empresas multinacionales o grupos financieros. También, a principios del siglo $\mathrm{XXI}$, se instaló en la región una empresa canadiense (Agostino Hermanos) que responde completamente a los imperativos propios del nuevo modelo de producción.

Durante los cuatro períodos de trabajo de campo, se realizaron 61 entrevistas en profundidad con trabajadores de la zona. En cada período intentamos entrevistar a las mismas familias con el objeto de reconstruir trayectorias familiares. En 1997 y 1999 , las entrevistas se realizaron en los domicilios. En su mayoría fueron entrevistas individuales realizadas a mujeres, en las que luego se incorporaron los hombres que volvían de la cosecha y los hijos mayores que volvían de trabajar o de la escuela. Esta situación de entrevista permitió observar, a través de las intervenciones de unos y otros, la manera en la que se construyen consensos familiares respecto de diferentes temas. En 2010, también se realizaron entrevistas individuales que se transformaron en colectivas, sólo que en esta ocasión quienes se incorporaron a la misma fueron los vecinos. Las entrevistas tuvieron lugar en la vereda lo que permitió que distintos vecinos fueran incorporándose a la charla. Esta situación de entrevista permitió observar el enfrentamiento de puntos de vista discordantes respecto de la transformación de la fisonomía de la región luego de la llegada de capitales extranjeros.

El artículo se divide en dos partes. En la primera parte, analizamos la institucionalización de la unidad indivisible casa/trabajo en el marco del estatuto de contratista. Para ello, analizamos por un lado el estatuto del contratista en términos legales, y por otro, el mundo laboral que se construye en torno a ese estatuto. En la segunda parte, analizamos la ruptura de la unidad casa/trabajo en tanto que consecuencia del proceso de recomposición de la industria vitivinícola. Por consiguiente, analizamos por un lado, el proceso de transformación de la agroindustria vitivinícola y su 
correlato en términos de recomposición de las relaciones laborales, y por otro, la reorganización del mundo laboral y social de los excontratistas de Barrancas.

\section{La casa y el trabajo como una unidad indivisible}

Si bien en el mundo agrícola la mayoría de los contratos de trabajo, ya sea como peón o como contratista, implican el derecho a una vivienda en la propiedad agrícola, fue la estabilidad en el tiempo propia de la relación contractual que unía al contratista y a su familia con el patrón lo que dio lugar a esa unidad indivisible que se transformó en el fundamento de las relaciones laborales y sociales en las regiones vitivinícolas de Mendoza.

El estatuto de contratista, en tanto que estatuto laboral, definió los límites de un campo de relaciones de trabajo posibles, al interior del cual sólo un cierto número de relaciones laborales se actualizaron, adoptando formas singulares que resultaron de la manera en que los actores involucrados se apropiaron de la reglamentación (Poblete, 2008a). Fue ese conjunto de relaciones laborales el que dio forma al modelo de organización del trabajo vitícola que permaneció vigente en Mendoza durante la mayor parte del siglo XX.

\subsection{El estatuto de contratista}

El contratista es un actor que aparece con el desarrollo de la vitivinicultura alrededor de 1880. Existieron en esa época tres tipos de contratista: el contratista de plantación, el contratista de viñas y el contratista de trabajadores. El primero tenía un contrato de arriendo de la tierra con el objetivo de plantar vides, que le permitió en algunos casos acceder a la propiedad. El segundo tenía un contrato de mantenimiento de la propiedad agrícola y de producción. El tercero se dedicaba al reclutamiento de cosechadores (Richard-Jorba, 2003: 19). Actualmente, sólo los contratistas de viñas siguen presentes en el sector, aunque su presencia disminuya paulatinamente. En 1936, año en el que se realizó el primer Censo Nacional de Viñedos, los contratistas trabajaban el 68\% del territorio cultivado (Salvatore, 1986: 332). En 1979, 43,3\% de la superficie implantada estaba a cargo de contratistas. Desde entonces hasta 1989 (último año para el que se tienen datos), la participación de los contratistas disminuyó hasta representar el 29,9\% (INV, 1989). Si bien la presencia de los contratistas en la actividad vitícola viene reduciéndose de manera constante desde mediados del siglo XX, el estatuto de contratista ha dejado una fuerte impronta en la organización del trabajo y en la estructuración de las relaciones sociales en las regiones vitícolas de Mendoza.

Este estatuto aparece en la legislación laboral como un estatuto especial en 1973. La ley 20.589 define al contratista de viñas y frutales como "la persona que, en forma individual o con su núcleo familiar, trabaja personalmente en el cuidado y cultivo de dichas especies, percibiendo como contraprestación [una] retribución" (art.1). La remuneración del contratista está compuesta por un sueldo mensual y por un porcentaje de la cosecha. El salario, pagado por los diez meses del año agrícola 
en función de las hectáreas trabajadas, es fijado por paritarias, e incluye el aguinaldo (art.12). El porcentaje de los beneficios de la cosecha que corresponde al contratista no puede ser inferior al 18\% (art.16). Según el artículo 17, "diez días antes de la cosecha, el contratista y el empleador deberán convenir el destino correspondiente al porcentaje del primero, el precio y su forma de pago."

El artículo 12 le otorga derecho a los beneficios de las leyes laborales, previsionales y sociales vigentes en ese momento: ley de accidentes de trabajo (9.688), ley de despidos (11.729), y asignaciones familiares.

El plazo mínimo de duración del contrato de trabajo es de un año agrícola. "No habiéndose denunciado se entenderá prorrogado por un nuevo año, y así en forma sucesiva, salvo que cualquiera de las partes hasta el último día de febrero de cada año notifique a la otra la voluntad de rescindirlo" (art.30).

Son obligaciones del empleador el "proporcionar vivienda adecuada a las necesidades del contratista y su familia", suministrar los insumos necesarios para realizar el trabajo agrícola - maquinarias, productos químicos, animales, etc.- (art.11). El contratista, por su parte, tiene la obligación de realizar todas y cada una de las tareas descritas de manera detallada en la ley ya que su incumplimiento es causal de ruptura del contrato (art.13). El contratista puede cumplir con dichas tareas con su grupo familiar o subcontratar personal.

Este estatuto establece una relación laboral con características especiales dado que el contratista aparece como un "trabajador subordinado atípico". Por una parte, se le reconoce un alto grado de autonomía en la gestión de su trabajo aún si el empleador provee los insumos y herramientas que le son necesarios para realizar las tareas agrícolas. También se le asigna la gestión del personal a su cargo. Al mismo tiempo, asume con el empleador los riesgos empresariales inherentes a la cosecha. Pero, por otra parte, recibe un salario mensual y las protecciones sociales asociadas al estatuto de asalariado, así como una vivienda.

\subsection{Del estatuto al mundo del contratista}

Lo que hizo que la unidad casa/trabajo constituyera el eje de las relaciones laborales fue la extensa duración de la relación contractual. Aún si se trataba de un contrato anual, casi por inercia, generalmente era renovado, incluso llegando a pasar de una generación a la otra. Esta continuidad en el tiempo llevó a los contratistas a pensar su lugar en la estructura laboral como un "puesto fijo". Esta forma de estabilidad contractual generó, al mismo tiempo, una fuerte implicación en el trabajo, la sensación de pertenencia a la propiedad agrícola y una relación particular con los patrones.

El hecho que el contratista viviera y trabajara en la misma finca durante años, sumado a las condiciones contractuales, llevó al contratista a gestionar el predio como si fuera propio. Dado que su ingreso principal (el porcentaje de la cosecha) dependía de la productividad de las hectáreas que tenía a cargo, el contratista asumía su trabajo con un alto nivel de compromiso. Además, a raíz de la renovación indefinida del contrato, las parcelas a cargo del contratista aparecían en el imaginario como la herencia que éste podía dejar a sus hijos. En términos de organización 
del trabajo, podemos decir que, gracias a la durabilidad de la relación contractual, el estatuto de contratista dio lugar al surgimiento de un mecanismo de autodisciplinamiento de la mano de obra muy eficaz.

La permanencia en la finca produjo también un fuerte sentimiento de pertenencia. "Soy de Toso", "soy de Flichman", son frases que aparecen con frecuencia en el discurso de nuestros interlocutores para marcar su identificación con una propiedad, lo que es al mismo tiempo, un modo de señalar su inscripción en un territorio preciso y en una comunidad. "Hace ya dos años que vivo acá, pero soy de Toso, tengo todavía todos mis amigos allá", nos explicaba una entrevistada que vivía a 1 $\mathrm{km}$ de la finca Toso.

Dada la imbricación del espacio vital con el lugar de trabajo, el mundo del contratista estaba fuertemente marcado por la relación que se establecía con el patrón. En este modelo de organización del trabajo, la proximidad con el patrón era considerada fundamental, al punto que la relación de trabajo parecía confundirse con una relación personal. Sin embargo, esta proximidad solía ser más imaginaria que real, dado que los patrones no vivían en las fincas, sino en la ciudad y solo en contadas ocasiones iban a las fincas. En efecto, los momentos en los cuales el patrón y el contratista se encontraban eran excepcionales. Esta imagen de una relación privilegiada entre el patrón y el contratista se alimentaba principalmente del rol social asignado al patrón en la región, así como de los espacios de negociación establecidos por la ley (la determinación del porcentaje de beneficios de la cosecha y el modo de renovación del contrato de trabajo).

En Barrancas, los patrones históricamente asumieron el rol de protectores de la comunidad, llenando los espacios vacíos dejados por las políticas sociales. En diferentes ocasiones, fueron ellos quienes participaron en el financiamiento de programas de ayuda alimentaria implementados en las escuelas de la zona y proveyeron medicamentos a los centros de salud. También construyeron escuelas y colaboraron en la construcción de centros de salud. Estas intervenciones permitieron consolidar la imagen del "buen patrón" a la cual se refieren con frecuencia los contratistas entrevistados. El "buen patrón" aparece así como el protector del conjunto de los trabajadores de la finca. Sin embargo, ese rol no tiene necesariamente un correlato a escala individual.

El patrón asumía el rol de benefactor exclusivamente a nivel de la comunidad. Sin embargo, la manera en la que asumía este rol funcionaba como un indicador de la buena disposición del patrón a negociar los aspectos de la relación laboral que el estatuto de contratista establece como negociables. La reconducción del contrato y el aumento del porcentaje de la cosecha eran entonces definidos en función de "juicios personales" basados en la "lógica del mundo doméstico" (Boltanski y Thévenot, 1991). De esta manera, la búsqueda de un mayor reconocimiento por parte del patrón, interpretada como una garantía de estabilidad del empleo y de seguridad de los ingresos, generaba en los contratistas diferentes tácticas caracterizadas por mayor disponibilidad que la estipulada por la ley.

En este modelo de organización del trabajo, la indivisibilidad de la unidad casa/trabajo, estructuraba además el universo social. Estos cuatro elementos - la 
permanencia en la misma finca, la manera en la que los contratistas se apropiaban del trabajo y del territorio, así como la relación personal que establecían con los patrones - contribuyeron a la construcción simbólica de un lugar de privilegio dentro de la estructura social local. El contratista era el trabajador rural con mayor jerarquía dentro de esa organización del trabajo. En el imaginario colectivo, aparecía como el segundo después del patrón. La autonomía que le otorgaba el estatuto en lo que se refiere a la organización del trabajo y a la contratación de jornaleros, así como la proximidad con los patrones en lo que respecta a los riesgos empresariales compartidos, situaba al contratista en una posición de superioridad en relación con los otros trabajadores. Esta posición de poder en el espacio social, sin embargo, no dejaba exentos a los contratistas de una gestión meticulosa de la condición de pobreza en la que vivían (Poblete, 2008b: 65).

\section{La casa y el trabajo como unidades independientes}

El proceso de recomposición de la industria vitivinícola que comienza en los años 90 implicó la redefinición y reorganización de las relaciones laborales. Por una parte, la reorganización de las relaciones laborales tiene que ver con la incorporación de nuevas tecnologías agroindustriales necesarias a la producción de vinos capaces de competir a nivel internacional. El uso de las mismas modificó de manera directa la demanda de mano de obra tanto respecto de la cantidad de trabajadores como del nivel de calificación de los mismos. Por otra parte, la adopción de nuevos principios de gestión de recursos humanos que priorizan las relaciones laborales flexibles y discontinuas entre el empleador y el trabajador, dio como resultado la ruptura de la unidad casa/trabajo. Esta entidad, planteada estatutariamente como indivisible, obligaba al empleador a responsabilizarse no sólo de la situación del contratista sino también de la de su familia, alojada dentro de su propiedad.

\subsection{El proceso de recomposición de la industria vitivinícola}

El proceso de recomposición de la industria vitivinícola resulta, por una parte, del agotamiento del modelo de producción existente, y por otra, de la promoción de un nuevo modelo agroindustrial estructurado en torno a la exportación de vinos finos.

El modelo anterior, centrado en la fabricación de vinos comunes destinados al mercado interno, entra en crisis a raíz de dos factores principales: un cambio en la pauta de consumo de vino y problemas en la gestión familiar-empresarial de los establecimientos vitivinícolas. Por una parte, se observa una constante disminución del consumo de vino de mesa dado que es reemplazado por otro tipo de bebidas. En 1970, el consumo era de 92 litros por persona y en 1994 de solo 43,2 litros. Por otra parte, la mayoría de las bodegas, constituidas como empresas familiares a finales del siglo XIX y principios del siglo XX, manifiestan importantes problemas de gestión al llegar a la tercera generación. Estos problemas se suman a la reducida 
capacidad de inversión que tienen estas empresas debido al endeudamiento adquirido durante los años 80 (Mellado, 2008: 355).

El nuevo modelo de producción, posibilitado por la apertura del mercado y la desregulación de la economía, se plantea como objetivo principal la producción de vinos de mayor calidad destinados a un mercado externo que había crecido un $50 \%$ entre 1988 y 1998 (Neiman y Bocco, 2005: 206). Este modelo presupone una gran inversión en términos de tecnologías agrícolas e industriales para poder desarrollar actividades productivas de alto nivel; así como también, el desarrollo de circuitos de comercialización internacional. Estos dos requisitos resultan imposibles de alcanzar para la mayoría de las empresas vitivinícolas nacionales que se encuentran con problemas de gestión y que no pueden obtener créditos que les permitan encarar ese proceso de reconversión agroindustrial (Collado y Rofman, 2005). Por lo tanto, los únicos actores capaces de participar de ese proceso eran las empresas extrajeras. Se calcula que entre 1990 y 1999 invirtieron 523,3 millones de dólares (Aspiazu y Basualdo, 2001: 126) y entre 2000 y 2005, otros 123,4 millones (INV, 2000, 2005).

La recomposición del sector vitivinícola se observa también en el aumento de las hectáreas cultivadas y del tipo de variedades implantadas. Gracias a las nuevas tecnologías de riego, se incorpora una gran cantidad de hectáreas a la producción vitícola. Luego de la pérdida de más del $30 \%$ de la superficie cultivada que se produce durante los años 80 , en los 90 la superficie permanece estable, observándose un crecimiento de casi 10\% entre 2002 y 2008 (INV, 1978-2008). Las nuevas plantaciones corresponden exclusivamente a las cepas más demandadas por el mercado internacional: Cabernet Sauvignon, Pinot Noir, Merlot, Chardonnay, Sauvignon Blanc y Malbec. Las hectáreas implantadas con este tipo de variedades aumentan en un 67,5\% entre 1991 y 2001 (INV, 1978-2008).

Este proceso de transformación de la agroindustria vitivinícola no afecta de manera homogénea al sector vitivinícola en su conjunto. Sino que estructura un modelo dual de producción (Bocco y otros, 2005) caracterizado por la superposición de dos marcos tecnológicos diferentes (Maclaine Pont y Thomas, 2009). Aún si la producción de vinos finos para la exportación aparece como el subsector más dinámico dentro de la vitivinicultura mendocina, la elaboración de vinos comunes destinada al mercado interno representa más de la mitad de la producción regional. Incluso, dentro de este subsector, muchas empresas han incorporado nuevas tecnologías agrícolas y vinícolas. Algunas de ellas han diversificado sus estrategias comerciales y hoy elaboran vinos finos tanto para el mercado interno como para el mercado externo.

Si bien la recomposición del sector implica la transformación de los modos de organización del trabajo, dentro de este heterogéneo universo no se ha conformado todavía un modelo propio de gestión de la mano de obra, aunque pueden observarse algunas tendencias. Las innovaciones en cuanto a la organización del trabajo aparecen principalmente en aquellos emprendimientos que participan directa o indirectamente del proceso de reconversión de la vitivinicultura. Este subsector está dominado por capitales extranjeros (Collado y Rofman, 2005) que han contribuido tanto a la concentración de la producción, como a la diversificación de los modos de 
participación en el sector vitivinícola. Actualmente, el $40 \%$ de los vinos finos es elaborado por cinco bodegas, entre las que se encuentran Chandon, Esmeralda, La Rural, López y Trapiche (Collado, 2001). A esta concentración se contrapone una enorme diversidad de estructuras productivas de diferentes tamaños. El Instituto Nacional de Vitivinicultura registra cerca de 900 bodegas en la provincia de Mendoza, muchas de las cuales son emprendimientos comerciales realizados con capitales extranjeros.

En lo que respecta al sector primario, la recomposición de la vitivinicultura se manifiesta como una tendencia hacia una mayor integración vertical. Por una parte las grandes bodegas aumentan su capacidad de producir materia prima con la compra e implantación de nuevas hectáreas. Por otra parte, los pequeños productores, sobre todo aquellos que producen uvas finas se transforman en proveedores "estables" de los grandes establecimientos. No existe entre ellos y los bodegueros ningún contrato escrito donde los últimos se comprometan a comprar la producción de los primeros a precios pre-establecidos. Quince o diez días antes de la cosecha, los bodegueros establecen la cantidad de uva que van a comprar y los precios. Si bien en la mayoría de los casos, las bodegas invierten en tecnología agrícola en esas propiedades, el riesgo empresarial (riesgo asociado a las incidencias climáticas en el caso de la agricultura) es asumido exclusivamente por el productor. Este modo de integración supone que los productores introduzcan nuevas tecnologías agrícolas y acepten el control de los ingenieros agrónomos y enólogos de las bodegas clientes durante el proceso productivo.

La incorporación de tecnologías como el riego por goteo automatizado, la malla antigranizo y el uso del sistema de conducción denominado "espaldero alto" conlleva la reorganización de las tareas agrícolas, y por consiguiente, implica una redefinición de la mano de obra demandada. Los nuevos sistemas de cultivo necesitan menos trabajadores, pero más especializados. Incluso el espaldero alto permite la automatización de ciertas labores. Cuando se compara la mano de obra requerida para trabajar los parrales (sistema clásico del modelo de producción de vino común) con la mano de obra requerida para el cultivo en espalderos altos (sistema de conducción de variedades finas), resulta que este último necesita alrededor de un $11 \%$ menos de horas/hombre por hectárea, pero un $12,5 \%$ más de horas trabajadas por obreros calificados (Perlbach y otros, 2005).

También se observa un aumento de los trabajadores temporarios, contratados directamente o a través de agencias de empleo eventual (Fabio, 2010). La cosecha explica la mayor participación de trabajadores temporarios en el proceso de producción vitícola tanto en aquellos establecimientos que producen uvas para vinos de calidad como en aquellos que elaboran uvas comunes. El $90 \%$ de los primeros y el 93\% de los segundos contratan cosechadores externos (Quantara y Goldfard, 2005). Datos publicados en los anuarios de la Dirección General de Estadísticas de Mendoza, muestran que durante el primer cuarto del siglo XX, en el período de cosecha, el número de trabajadores se triplicaba (Salvatore, 1986: 244). Actualmente, la situación parece ser la misma. Los trabajadores permanentes representan sólo $23 \%$ del total de trabajadores vitícolas, y los temporarios 77\% (COVIAR, 2005). Sin 
embargo hoy, los trabajadores temporarios son también solicitados para realizar otras tareas estacionales.

El proceso de recomposición de la vitivinicultura también trajo aparejado un cambio en los modos de contratación. La figura del contratista disminuye aún más su presencia al aumentar el número de asalariados en el sector primario, sobre todo en los grandes establecimientos agrícolas (Mingo y Berger, 2009). Estos establecimientos organizan el trabajo en torno a un reducido número de asalariados y un gran número de obreros temporarios contratados a través de agencias de empleo eventual o a través de cooperativas de trabajo. Por su parte, los pequeños establecimientos prefieren utilizar la contratación de jornaleros, pagados al día, a la semana o por tarea (al tanto).

Los contratistas, que fueron los pilares del modelo de organización anterior, con lo que esto implica en términos de posiciones sociales, se encuentran, durante el comienzo del proceso de reconversión de la vitivinicultura, en una posición marginal o casi completamente excluidos. Con el correr de los años, algunas empresas volvieron a utilizar el estatuto de contratista, pero esta vez despojándolo de su característica principal: la indivisibilidad de la unidad casa/trabajo. Porque aún si se rompe la unidad casa/trabajo que deja al patrón exento de toda responsabilidad respecto de las condiciones de vida del contratista y su familia, el estatuto de contratista sigue siendo un mecanismo eficaz de autodisciplinamiento de la mano de obra.

\subsection{La reestructuración del mundo del trabajo en Barrancas}

A principios de los 90, en Barrancas había tres bodegas que concentraban la mayoría de las hectáreas cultivadas: Toso, Flichman y Martelén.

La bodega Toso — propiedad de la familia Toso-, desde los años 60 comienza a pasar a manos del grupo Llorente Hermanos. Este grupo, que adquiere importancia en los años 50 como distribuidor de bebidas, actualmente concentra negocios relacionados con diferentes agroindustrias. En 1960, la familia Toso y Llorente Hermanos se asocian para comprar una tradicional bodega de la zona. En 1981, debido a problemas financieros de la familia Toso, Llorente compra el $45 \%$ de las acciones de esa bodega, y en 1995, controla el total de las acciones. En 1997, cuando el diario Los Andes vende al grupo AGEA/Clarín y al grupo La Nación sus propiedades, Llorente adquiere la bodega Martelén (propiedad de ese grupo). Al año siguiente, Llorente se asocia con Disney Latinoamérica para aumentar la superficie cultivada, priorizando el cultivo de uvas finas. Hoy el grupo Llorente Hermanos cuenta con un predio de 400 hectáreas, donde 227 están cultivadas. La bodega Toso, que produce 6 millones de litros por año, es asesorada por el famoso enólogo californiano Paul Hobbs ${ }^{1}$.

${ }^{1}$ En el nuevo modelo de producción vitivinícola, los enólogos adquieren un protagonismo inusitado (Heredia, 2010). 
La bodega Flichman, propiedad de la familia con ese nombre, a raíz de problemas económicos fue vendida en 1983 a un grupo económico argentino (grupo Werhein). En 1997, el grupo Sogrape (grupo portugués especializado en la producción de bebidas alcohólicas) compró al grupo Werthein el 60\% de las acciones de la bodega y finca Flichman. El grupo Wethein conservó el 40\% y la dirección de la empresa. Más tarde, el grupo portugués adquirió la totalidad de las acciones. La inversión de 15 millones de dólares que realizó el grupo Sogrape fue destinada a la construcción de una nueva bodega con tecnología de última generación y a la implantación de nuevas viñas (Aspiazu y Basualdo, 2001: 129). La finca de 750 hectáreas tiene hoy 310 cultivadas. Tanto la bodega Flichman como la bodega Toso muestran una estrategia combinada de producción de vinos finos a bajo precio y de vinos de mayor calidad destinados tanto al mercado interno como al mercado externo.

En 2003, se instala en la región un grupo económico canadiense, dedicado a la construcción y a los negocios inmobiliarios en ese país. Este grupo económico familiar, denominado Agostino Hermanos, compra 60 hectáreas cultivadas y 80 hectáreas sin cultivar que formaban parte de la finca Martelén, así como también incorpora nuevos terrenos. La finca cuenta hoy con 225 hectáreas cultivadas. En 2005, se construyó una bodega de alta tecnología de vinificación, que tiene capacidad para almacenar 3 millones de litros de vino. Finca Agostino Winery produce vinos de alta calidad principalmente destinados al mercado externo, y varietales para el mercado interno. Se calcula que la inversión inicial de este grupo económico en la región de Barrancas supera los 6 millones de dólares (MDZ, 01/12/2008).

Estos tres grupos económicos, aún con el mismo objetivo de, por un lado, flexibilizar las relaciones laborales, y por otro, reducir los costos del trabajo, eligen diferentes modos de organizar el trabajo. En todos ellos, la casa y el trabajo aparecen como unidades separadas. La explotación vitícola del grupo Llorente Hermanos está a cargo de un "capataz" que subcontrata a cooperativas de trabajo para la realización tanto de tareas permanentes como temporales. El grupo Sogrape, en cambio, maneja sus hectáreas cultivadas con el trabajo de asalariados, bajo la tutela de un capataz, a quienes se suman trabajadores temporarios contratados a través de agencias de empleo eventual. Por su parte, el grupo Agostino Hermanos eligió recuperar el estatuto de contratista, adaptándolo a las expectativas de un proceso productivo centrado en la calidad del producto.

En el análisis de estos nuevos esquemas de organización del trabajo vitícola, sobre todo de aquellos que involucran nuevamente a los contratistas como figura central, es necesario distinguir dos momentos clave. El primero es el de la desestructuración del sistema anterior, es decir el momento en el que los contratistas pierden su contrato y tienen que buscar alternativas habitacionales en una región donde no estaba previsto que la casa y el trabajo funcionaran como unidades sepa- 
radas. El segundo momento es el de la recomposición de las relaciones laborales a partir de una nueva estructuración del espacio habitacional que aparece como alternativa al modelo anterior.

\subsubsection{La ruptura de la unidad casa/trabajo: la pérdida del contrato}

Con la venta de las fincas, las bodegas y la implantación de nuevos emprendimientos, el mundo del contratista, tal como estaba organizado en Barrancas hasta mediados de los años 90, se ve completamente desestructurado. El traspaso de propiedades se realiza sin que los contratistas sean informados. Durante el trabajo de campo realizado en 1995, las personas entrevistadas hablaron de la venta de las fincas y las bodegas como si fuera un rumor. "Parece que van a vender Martelén", nos comentaba un contratista. "El contratista del fondo me dijo que ya habían vendido, pero yo tengo todavía mi contrato, no sé si es verdad, pero quien sabe..."

El primer signo de que las cosas estaban cambiando percibido por los contratistas fue la suspensión del pago de los salarios. Uno de nuestros interlocutores nos comentaba: "hace tiempo que la finca anda mal, muy mal. No te pagaban. Después de un mes o dos que no nos pagaban, empezaron a echar gente..." Si bien no era la primera vez que se producía un traspaso de propiedades agrícolas o de bodegas, era la primera vez que se traducía en la pérdida de sus fuentes de trabajo. Hasta ese momento los cambios de propietarios sólo habían generado una cierta rotación en el espacio, pero nunca el desempleo, desempleo que ponía en riesgo su permanencia en la región. Lo que parecía incomprensible para nuestros interlocutores era el hecho que no hubiera lugar para ellos en ese nuevo modelo de organización del trabajo. La automatización de algunas tareas o la voluntad de reducir los costos laborales fijos no aparecían en el discurso de los entrevistados como factores explicativos de los despidos. El primer criterio que evocaban era la edad:

Jorge - si, acá vendieron y dejaron a toda la gente sin trabajo, a los contratistas todos los dejaron con la olla para abajo. Y les dieron una miseria de plata. Porque contratistas que estaban por cobrar, tendrían que haber cobrado ese tiempo que cosecharon como diez mil pesos cada contratista. Y les dieron dos mil quinientos, tres mil quinientos y cobrá y quedate calladito. Yo tenía que cobrar diez mil y pico, y cobré tres mil ochocientos. Y pagan $70 \%$ y chau, no pagan más. Que vas a hacer... Compró Arizu y puso todo boliviano y a nosotros no. $Y$ desgraciadamente hay un encargado que no nos quiere a nosotros. Directamente no tenemos donde enganchar un laburo acá. Y siguen despachando gente. Y pasando los cuarenta años no te dan trabajo, tampoco. Y yo tenía 49 así. Así que si uno llega a los 51, como dicen, se tiene que matar (se ríe muy fuerte). 
Claudia - se ríe porque mi hijo dice que a él porque tiene más de 50 no le dan trabajo y a él porque tenía 17 no le daban. Ahora tiene 18 y al final consiguió. Ahora es el único que está trabajando...

Jorge - yo estoy cosechando... como una changa. Lamentablemente en esta finca no te dan trabajo al día porque no les conviene... ${ }^{2}$

La edad aparece como un criterio de exclusión pero no es la edad en sí misma la causal de despido, es decir la pérdida de las capacidades de trabajo de los contratistas mayores de cincuenta años, sino el hecho de que estos contratistas tienen mayores dificultades para aceptar las nuevas reglas de juego, ya sea en término de estatutos laborales, ya sea en cuanto al uso de nuevas tecnologías. El despido de los contratistas mayores de cincuenta años indirectamente impone a la siguiente generación la aceptación de relaciones laborales más flexibles, que son las que proponen las empresas. La pérdida del contrato del trabajador principal obliga a los trabajadores secundarios — principalmente hijos - a aceptar trabajar bajo estatutos laborales menos protegidos, como por ejemplo el de jornalero o el de trabajador autónomo (Poblete, 2008b). Sin contrato y bajo la amenaza de desalojo, los excontratistas experimentan, a finales de los años 90, una situación de extrema vulnerabilidad.

Una entrevistada nos comentaba en 1999:

Alejandra - ahora está todo vendido. Ya el año pasado empezaron a vender partes y lo único que quedó de la finca son estas casas que vos ves juntitas, y algunos parrales para atrás. Pero después todo está vendido. Antes era todo lo mismo, la bodega y todo. Y la gente... la que ha arreglado con alguno, está con los dueños nuevos. Otros que no arreglan se van, porque bueno, les piden la casa, porque ya es del nuevo dueño. Y si no arreglan contrato o algo con ellos se tienen que ir porque la casa es de acá de la finca. Y ellos compran con la casa pero sin gente. Antes alquilaban las casas. Pero como empezó a haber así, movimiento, que despedian, que se iba gente. Necesitaban las casas para venderlas o para cualquier otra cosa, y no alquilaron más. La gente que alquilaba se tuvo que ir a otro lado. Normalmente se vendian las fincas pero la gente se quedaba. Uno se iba un poco más allá, un poco más acá, pero siempre dentro de la finca o en la de enfrente. No es que uno digamos, se va para el lado de Maipú, el centro o cualquier otro lado.

Dos elementos nuevos aparecen en este proceso de reestructuración de la producción vitivinícola. El primero es que en un lapso de aproximadamente cinco años, la mayor parte del territorio cultivado y las bodegas de la región cambian de manos. Ya no se trata sólo de los trabajadores de una finca que buscan reubicarse en otra

\footnotetext{
${ }^{2}$ Entrevista realizada en 1997.
} 
luego de que ésta fuera vendida, sino de un período de movilidad generalizada donde la posición de la mayoría de los trabajadores rurales de la zona en la organización del trabajo parece incierta.

El segundo elemento que se presenta como novedoso es el hecho de que "compraron las casas pero sin la gente". Por consiguiente, aquellos que perdieron el contrato - como nos explicaba Alejandra - "se tienen que ir". El problema es que la mayoría de los trabajadores de la zona "no tiene a dónde ir".

Como nos comentaba Laura:

Laura - cuando nosotros nos vinimos, Llorente todavía estaba en tratativas, y nosotros no sabíamos a dónde miércoles nos íbamos a ir. Y buscamos para alquilar, y no hay ni para nada. Así que andábamos así...desesperados. Y no tenías a dónde irte. Y el problema no es un hogar, sino un lugar dónde meter a los niños. ${ }^{3}$

En la región, hay muy pocas casas para alquilar. El mercado inmobiliario fue siempre reducido y funcionaba de una manera muy particular, dado que los alquileres eran bajísimos, y no se producían desalojos por falta de pago. Las empresas familiares preferían alquilar algunas casas a los obreros mensualizados, aún a precios irrisorios, antes que ver crecer asentamientos dentro de sus fincas.

Las casas que se encuentran en la zona son, en su mayoría, de los dueños de las fincas. Sólo en contados casos, los trabajadores acceden a una vivienda. A veces, esto sucede porque el patrón les regala la casa aunque esté dentro de su finca. En otras ocasiones, los trabajadores participan de emprendimientos colectivos (como fue el barrio Flichman), o participan de proyectos familiares, como en el caso de la familia de Laura.

Laura - te digo, el año pasado no sabíamos qué hacer, a dónde irnos porque empezamos a buscar, fuimos acá, fuimos al Alto, fuimos a Tres Esquinas, y ni para alquilar. Así que no, no sabiamos qué hacer. Hasta que nos salió la oportunidad del lote. Que nos juntamos con unos tíos de mi marido porque lo que nos habían pagado en la bodega era poco. Estamos levantando una casita. Hemos empezado con una pieza y con una cocina chiquita, pero hemos levantado hasta la altura de la ventana. Mi marido quiere terminar de levantarla porque dice, por cualquier cosa. Aunque sean dos piezas, y ya nos podemos meter ahi. ${ }^{4}$

Lo problemático de la indivisibilidad de la unidad casa/trabajo ya había sido identificado por algunos propietarios de fincas en años anteriores. Es por ello que el Barrio Flichman aparece como un primer intento de separar esos dos elementos. A

\footnotetext{
${ }^{3}$ Entrevista realizada en 1997.

${ }^{4}$ Entrevista realizada en 1997.
} 
principios de los 90, los dueños de la finca Flichman donaron unos terrenos para que se construyera un barrio. A través de la organización de una cooperativa, en acuerdo con el Instituto Provincial de la Vivienda que les daba un financiamiento de 25 años, y en colaboración con la Municipalidad de Maipú que les donó materiales, se construyeron 38 casas. Este emprendimiento permitió que los trabajadores de mayores ingresos accedieran a la propiedad. Según algunos de nuestros entrevistados, la cuota mensual era muy alta para la mayoría de los contratistas. Por consiguiente, los que compraron no trabajaban en actividades agrícolas, sino como técnicos en la empresa petrolera que tiene explotaciones en la zona o en actividades comerciales en la ciudad de Maipú (a $25 \mathrm{~km}$ de Barrancas). Los contratistas siguieron entonces dependiendo del contrato de trabajo para poder acceder a una vivienda.

Entre 1995 y 1999, el mercado de trabajo agrícola en Barrancas perdió una de sus características distintivas: la indivisibilidad de la unidad casa/trabajo. Si ese mercado de trabajo había logrado mantener un cierto equilibrio entre la oferta y la demanda de empleo durante tres décadas, fue en parte porque el acceso condicionado a las viviendas funcionaba como una variable de ajuste. En ese esquema, el aumento de la tierra cultivada implicaba el aumento de las viviendas. La evolución demográfica dependía de la capacidad de hacinamiento de las familias extendidas. Sin embargo, el hacinamiento tenía sus límites dado que los contratistas no estaban autorizados a realizar modificaciones en las casas que recibían. En ese mercado de trabajo regulado por las viviendas, el desempleo nunca tuvo un lugar específico. El desempleo fue siempre esporádico, o un período de transición cuando se cambiaba de contrato. Por esta razón, la aparición de desempleo sin perspectivas de recontratación significó, para los excontratistas, un período de mucha incertidumbre. En este período de transición, los excontratistas tuvieron que encontrar una solución al problema habitacional. Fue, durante ese período, que los distintos modelos de organización del trabajo que se observan hoy en la región tomaron forma.

\subsubsection{La recomposición de las relaciones laborales: la casa con o sin trabajo}

Dado que no volvimos a Barrancas entre 1999 y 2010, nos es imposible determinar períodos dentro de ese largo proceso de recomposición de las relaciones laborales. Cuando llegamos a Barrancas en enero 2010, nos encontramos con que la mayoría de los contratistas que habíamos entrevistado en años anteriores vivía en casas de las que eran propietarios. "Ahora que estamos en lo propio", "desde que vivimos en lo de nosotros", "y... tenemos la casita", eran frases que aparecían en todos relatos. "Porque las casas nos las dieron...", nos comentó Raúl.

Raúl - viste que cuando vendió Martelén, vendió las casas pero sin las gentes. Y bueno, se armó un revuelo porque las gentes no tenían a donde ir, y no se iban, y no se iban... Y ya Martelén quería terminar con todo. Viste como son los del diario, querían liquidar todo, y ya, salir del asunto. Así que como no nos habían pagado más que el 70\%, y nos debían de la cosecha, nos dieron las casas... 
Estela - mirá, los de Martelén nos tenían que dar la indemnización, porque cuando nos quitaron el contrato no nos dieron ni el porcentaje. Andaban con problemas de plata, que por eso vendieron, decían... Pero no nos dieron ni el porcentaje. Entonces, parece que los abogados les dijeron que nos tenían que dar las casas. Unos muchachos de allá fueron al sindicato, pero no pasó nada. Pero igual, no sé, al final nos dieron las casas. Igual, quien las iba a querer si estaban destrozadas. ${ }^{5}$

En la finca Martelén había alrededor de 45 casas. Unas 30 casas situadas al borde del carril (ruta provincial 14) y 15 casas situadas al interior de la finca. Estas últimas, de acuerdo con los relatos de nuestros entrevistados, fueron arregladas y "se las dieron a los tractoristas y al capataz". Esto significa que la vivienda sigue siendo parte de los beneficios del contrato de trabajo para aquellos trabajadores que han sido contratados para realizar tareas agrícolas o vitivinícolas en calidad de asalariados. Sin embargo, no todas las casas ubicadas en el interior de la finca sirvieron para alojar a los trabajadores permanentes, la mayoría fue dada en alquiler a trabajadores rurales de la zona que participan de manera transitoria en las labores de las fincas aledañas.

En cambio, las casas situadas al borde del carril fueron otorgadas a modo de indemnización a los excontratistas de Martelén. Muchos de ellos vivían en esas casas cuando trabajaban en esa finca, otros se mudaron una vez que les fueron otorgadas. Este hecho no sólo cambió la fisonomía del carril dado que ahora las casas se encuentran pintadas y bien cuidadas, sino que - por sobre todo - posibilitó el desarrollo de nuevas formas de organización del trabajo vitícola, así como también la recomposición de las relaciones familiares y de las posiciones sociales de los actores de la región.

La propiedad de la vivienda permitió en primer lugar la transformación de la estructura familiar, y por consiguiente, el establecimiento de nuevas estrategias de reproducción familiar. El hecho que los dueños de las fincas prohibieran a los contratistas hacer modificaciones en las casas que les daban, funcionaba como un límite a la extensión de la familia. En la mayoría de los casos, las familias que visitamos entre 1995 y 1999 eran familias nucleares, es decir constituidas por un matrimonio y los hijos e hijas solteros. Pero, a partir del momento en que se vuelven propietarios, los excontratistas comienzan a agrandar sus viviendas, lo que permite la convivencia de numerosos miembros de una misma familia. De las 20 familias que visitamos en 2010, 17 eran familias extendidas. El domicilio era compartido por varios matrimonios, de distintas generaciones, con sus hijos.

La posibilidad de alojar a distintos miembros de la familia en la casa propia, dio lugar a diferentes formas de gestión y producción conjunta de ingresos familiares. Si bien la literatura sobre el trabajo rural, y aquella relativa a la estructuración de la

\footnotetext{
${ }^{5}$ Entrevista realizada en 2010.
} 
familia en clases populares, presentan a la cohabitación de las familias extendidas como generadora de estrategias de cooperación entre los miembros de la familia, y por consiguiente estrategias de integración diferenciales en el mercado de trabajo (Attias-Donfut, 1995; Dechaux y Herpin, 2004), en Barrancas esta situación es relativamente nueva. Al funcionar la familia extendida como una unidad de producción, cada uno de sus miembros - individualmente - puede aceptar relaciones laborales que presenten distintos niveles de flexibilización y/o precarización de las condiciones laborales, dado que es el conjunto de formas de inscripción en el mercado de trabajo el que garantiza la subsistencia del grupo familiar.

En segundo lugar, en términos de la organización del trabajo vitícola, la propiedad de la vivienda permitió que los excontratistas pudieran insertarse en el mercado de trabajo local bajo distintas formas contractuales, incluso fuera de todo contrato legal. Pero también, el hecho de poseer su propia casa fue lo que les permitió volver a participar en el mercado de trabajo en tanto que contratistas. Como dijimos anteriormente, uno de los modelos de organización del trabajo agrícola que parece cristalizarse en la actualidad es aquel que recupera la figura del contratista para reinterpretarla en clave de flexibilidad laboral.

El grupo Agostino Hermanos reivindica públicamente su elección de recuperar del olvido esta categoría tradicional del trabajo rural mendocino. El uso de este estatuto es presentado como un elemento distintivo ya que permite conjugar el saber local con los valores internacionalmente reconocidos. El contratista aparece entonces como el personaje central del mundo tradicional del vino, cuyo trabajo y dedicación permiten asegurar la producción de materia prima de mayor calidad, calidad que hoy se asocia directamente con la de los vinos.

Esta revalorización del estatuto de contratista no es sino un modo de legitimar simbólicamente un modelo de organización del trabajo que tiende a hyperresponsabilizar a los trabajadores, desresponsabilizando a los empleadores. Bajo el régimen del contratista, el trabajador aparece como el único responsable de las tareas que realiza, y al mismo tiempo, comparte con su empleador los riesgos empresariales dado que la mayor parte de su compensación financiera depende de los resultados que obtenga.

A pesar de las cargas y los riesgos que impone al contratista este estatuto, aquellos que "perdieron el contrato" y que luego de varios años volvieron a ser contratados en calidad de contratistas celebran esta situación. El volver a "tener un contrato" además de una inserción laboral, significa la recuperación de una identidad profesional, al mismo tiempo que representa un modo de reconocimiento social. José nos contaba en 2010:

José - después que perdi el contrato, nadie me daba trabajo a mi edad. $Y$ me decían que hiciera la jubilación, pero bueno, usted sabe que la jubilación tarda en salir. Y yo necesitaba trabajar, y así, trabajar al tanto no rendía nada... El trabajo al tanto es para los más jóvenes, que corren, que cargan cincuenta tachos, que corren con los tachos, que sé yo... A mi no me rendía... yo quería trabajar un contrato, es lo que hice toda mi vida, y lo que yo sé hacer... 
Para los contratistas, estos nuevos contratos, que implican estabilidad laboral, les devuelven su visibilidad en el espacio social. Si en el antiguo modelo los contratistas eran los únicos trabajadores estables, hoy además, son propietarios de sus viviendas. Los signos de distinción aparecen precisamente expuestos en las fachadas de las mismas: puertas de con molduras, rejas de estilo, baldosas en las veredas, etc.

La revalorización del estatuto de contratista que hace pública el grupo Agostino Hermanos no implica el restablecimiento del estatuto tal como existió, sino la adaptación del mismo a los nuevos intereses y necesidades de esta agroindustria.

Al rehabilitarse el estatuto de contratista, se reactualizan con él las relaciones de tipo parternalista que envuelven a las relaciones laborales. Como nos decía Pedro, cuando hablaba de los hermanos Agostino, "estos no son patrones, estos son una familia". Reaparece en esta frase la imagen clásica de los patrones tradicionales del modelo anterior: patrones cercanos afectivamente; patrones que consideran al trabajador como "parte" de su familia; patrones que son familias, es decir empresas familiares. Esta imagen de los patrones como familia se contrapone a la imagen que tienen los trabajadores de los grupos económicos que poseen las otras explotaciones vitícolas de la zona. Un trabajador nos decía en 1997: "estos... todos estos que vienen de afuera, no tienen ni cara. Nunca dan la cara. El único que sale con cara de perro es el capataz, pero ellos... nunca".

Este compromiso mutuo da lugar a negociaciones ah doc del porcentaje, es decir a negociaciones del porcentaje de la cosecha que se alejan de lo establecido por ley. Los contratistas entrevistados comentaron que cobraban sólo el 15\% de la cosecha. Según ellos, esa disminución del porcentaje está asociada al hecho de que ellos son propietarios de su casa. "Te dan el $15 \%$, y está bien. Antes te daban el $18 \%$ porque te tenían que dar la casa", nos explica José. La lógica que sustenta este argumento no aparece claramente a primera vista sobre todo cuando, gracias a la propiedad de la vivienda, los contratistas tienen mayores márgenes de negociación con el patrón. Si bien el contrato como contratista significa volver a tener estabilidad en el trabajo, y el reconocimiento social que ese estatuto otorga, la pérdida del mismo no pone a los trabajadores en la misma situación de riesgo que antes. La falta de contrato, es decir la falta de los ingresos que ese contrato genera, puede ser remplazada por otro tipo de ingresos, ya sea que resulten de trabajos temporarios, ya sea que provengan de subsidios sociales. Los contratistas entrevistados subrayaron, en distintas ocasiones, la importancia de la estabilidad dada por la propiedad de la vivienda. Ella posibilita la multiplicación de estrategias de inserción en el mercado de trabajo de los distintos miembros de las familias extendidas.

\section{Conclusiones}

Paradójicamente, la ruptura de la unidad casa/trabajo generó un modo de organización del trabajo que logró conjugar flexibilidad y precariedad laboral con estabilidad. La estabilidad anteriormente producida por la renovación casi automática del contrato del contratista, hoy está dada por su permanencia en el espacio, permanen- 
cia que resulta de la propiedad de su vivienda. Si antes el contratista permanecía inmóvil en la finca en la que tenía su contrato, hoy puede participar de actividades diversas en distintas explotaciones. Puede tener a su cargo un número limitado de hectáreas por contrato, y aumentar sus ingresos a través de trabajos temporales realizados en otras fincas.

Esta movilidad que adquiere el trabajador constituye un elemento clave en la constitución de relaciones laborales flexibles. El hecho que el trabajador "no quede en la calle" cuando pierde el contrato, dado que su estabilidad en el espacio le permite generar distintas estrategias de inserción en el mercado de trabajo, libera a los empleadores de la responsabilidad de asegurar la estabilidad laboral de los contratistas. La desvinculación del contratista de una finca particular no se traduce en problemas de reubicación de familias dentro de ese espacio social. A partir, de la posesión de la vivienda, y de la ampliación de la familia que esta conlleva, la gestión de los recursos familiares deja de depender de un empleo principal relativamente estable. Las inscripciones precarias en el mercado de trabajo, características de los mercados de trabajo rurales, pueden ser sostenidas sin llegar a ser demasiado problemáticas, gracias a la estabilidad que genera la propiedad de la vivienda.

Para las empresas instaladas en la región, que los trabajadores sean propietarios de sus domicilios, y que por ende puedan asumir relaciones de trabajo aún más precarias, se traduce indirectamente en una reducción de los costos laborales. Por una parte, sin que eso implique mayores conflictos sociales, los empresarios pueden proponer jornadas legales de trabajo combinadas con tareas no declaradas. Por otra parte, el Estado aparece como un factor de reducción del costo del trabajo, ya que la mayoría de los trabajadores de la zona, por su condición de pobreza, reciben distintos tipos de subsidios sociales: planes Jefes y Jefas, pensiones no contributivas -por viudez o discapacidad-, jubilaciones de amas de casa, y ahora, asignaciones universales por hijos.

Esta combinación de propiedad de la vivienda con subsidios sociales puede tener tanto efectos positivos para las empresas, como efectos negativos. Si bien los trabajadores están en condiciones de aceptar relaciones laborales más precarias en términos estatutarios y remuneradas por debajo de los valores establecidos por las convenciones colectivas, también pueden no tener interés en aceptar esas condiciones laborales. La casa propia puede implicar tanto la movilidad de los trabajadores disponibles como su contracara, la inmovilidad completa.

Actualmente, la falta de trabajadores para realizar las tareas temporarias que requieren mayor mano de obra (la cosecha y la poda) ponen en cuestión los distintos modelos de organización del trabajo que se cristalizaron a principios del siglo XXI. Ningún modelo, ya sea aquel que prioriza al estatuto de asalariado rural, aquel que privilegia la gestión de personal a través de cooperativas de trabajo o empresas de empleo eventual, o aquel que pone en el centro al estatuto de contratista, ha podido resolver el dilema central del nuevo modelo productivo: cómo conseguir trabajadores capacitados y disponibles que acepten condiciones laborales hiperflexibles y altamente precarizadas, a cambio de bajos salarios. 


\section{Referencias bibliográficas}

Aspiazu, D. y Basualdo, E. (2001). El complejo vitivinícola argentino en los noventa: potencialidades y restricciones. CEPAL.

Attias-Donfut, C. (1995). Le double circuit de transmission. En C. ATTIASDONFUT (Coor.), Les solidarités entre générations. Paris : Nathan.

Bocco, A. y otros (2005). Reconversión y empleo en la industria del vino. Estructura productiva y dinámica del empleo en el complejo vitivinícola: un análisis del sector bodeguero nacional, Ministerio de Trabajo, Empleo y Seguridad Social.

Boltanski, L. y Chiapello, E. (1999). Le nouvel esprit du capitalisme. Paris: Gallimard.

Boltanski, L. y Thévenot, L. (1991). De la justification: les économies de la grandeur. Paris: Gallimard.

Collado, P. (2001). Mercado de trabajo en Mendoza: transformaciones y perspectives. Actas del $5^{\text {to }}$ Congreso de la ASET.

Collado, P. y Rofman, A. (2005). El impacto de la crisis de los años 2001-2002 sobre el circuito agroindustrial vitivinícola y los agentes económicos que lo integran, IV Jornadas Interdisciplinarias de Estudios Sociales y Agroindustriales. Buenos Aires. FCE-UBA.

COVIAR (2005). http://www.vitivinicultura2020.com.ar/

Dechaux, J-H. y Herpin, N. (2004). Entraide familiale, indépendance économique et sociabilité, Économie et Statistique, Núm. 373, 3-32

Fabio, J-F. (2010). Regulación social de la transitoriedad. El Mercado de trabajo en la producción de uvas en Mendoza, Argentina. Cuadernos de Desarrollo Rural, Vol. 7 Núm. 64, 33-57

Fabre, P. (2005). La privatización de Bodegas y Viñedos Giol. Una experiencia exitosa. Revista de la CEPAL, Buenos Aires, 1-43

Heredia, M. (2010). Las clases altas frente al nuevo espiritu del capitalismo. El caso de los bodegueros mendocinos y la reconversión vitivinícola, LASA 2010, Toronto, Canadá, 6-9 de octubre.

Instituto Nacional de la Vitivinicultura (INV), Anuarios: desde 1978 hasta 2008. 
Maclaine Pont, P. y Thomas, H. (2009). Como fue que el viñedo adquirió importancia? Significados de las vides, calidades de las uvas y cambio socio-técnico en la producción vinícola de Mendoza. Apuntes de Investigación, Núm.15, 77-96.

Mellado, V. (2008). Empresariado y vitivinicultura: trayectoria y caída del grupo Greco. En A-M. Mateu, y S. Stein, (comps.) El vino y sus revoluciones. Una antología histórica sobre el desarrollo de la industria vitivinícola argentina. Mendoza: EDIUNC.

Mingo, E. y Berger, M. (2009). Asalariados rurales en el Valle de Uco (Mendoza, Argentina). Mundo Agrario, Vol. 10 Núm. 19, http://www.mundoagrario.unlp.edu.ar/numeros/no-19-2do-sem-2009

Neiman, G. y Bocco, A. (2005). Estrategias empresariales y transnacionalización de la vitivinicultura en la Argentina. En J. Barbosa Cavalcanti y G. Neiman (comp.), Acerca de la globalización en la agricultura. Territorios, empresas y desarrollo local en América Latina. Buenos Aires: Ciccus.

Ospital, M-S. (2009). Modernización estatal y regulación económica en provincias vitivinicultoras. Mendoza, 1936-1946, Mundo Agrario, Vol. 9 Núm.18, http://www.mundoagrario.unlp.edu.ar/numeros/no-18-1er-sem-2009

Perlbach, I., Calderón, M. y Ríos Rolla, M. (2005). La generación de empleo en la cadena vitivinícola. A través de la matriz de insumo producto, Actas del $7^{\text {mo }}$ Congreso de la ASET.

Poblete, L. $\left(2008^{\mathrm{a}}\right)$. De la gestion de l'autonomie. Parcours de travailleurs autonomes argentins dans les années 90 . Tesis de doctorado en sociología de la Escuela de Altos Estudios en Ciencias Sociales de París, Francia. Publicada en línea por el Centre pour la communication scientifique directe-Centre National de la Recherche Scientifique http://tel.archives-ouvertes.fr/tel-00407491/fr/

Poblete, L. (2008b) De la pauvreté stable à l'instabilité dans la pauvreté. Les contratistas de la région vitivinicole de Mendoza (Argentine). Études Rurales, Núm. 181, 61-73

Quaranta, G. y Goldfarb, L. (2005). La mano de obra en las producciones de vid cuyanas, Actas del $7^{\text {mo }}$ Congreso de la ASET.

Richard-Jorba, R. (2003). El mercado de trabajo vitivinícola en la provincia de Mendoza y los nuevos actores. El "contratista de viña": aproximación a un complejo sistema de empresarios y trabajadores, 1880-1910. Revista Interdisciplinaria de Estudios Agrarios, Núm. 18, 5-37.

Salvatore, R. (1986). Control del trabajo y discriminación el sistema de contratistas en Mendoza, Argentina, 1880-1920", Desarrollo Económico, Vol. 26 Núm. 102, 229-253 